\title{
Polaridades en tensión para una adecuada interpretación de las Escrituras en la Iglesia
}

\author{
Rodrigo Polanco $F^{*}$ \\ FACULTAD DE TEOLOGÍA \\ PONTIFICIA UNIVERSIDAD CATÓLICA DE CHILE
}

La Constitución Dogmática sobre la Divina Revelación, Dei Verbum, afirma que la asamblea conciliar, i.e. la Iglesia, «escucha religiosamente y proclama fielmente la Palabra de Dios» (DV 1), ya que ella «recibió de Dios el mandato y el ministerio de conservar e interpretar la palabra de Dios» (DV 12). Se percibe de inmediato la ineludible relación de necesidad mutua -pero también de crítica- que se da entre exégesis/hermenéutica bíblica e Iglesia, en cuanto esta última es una comunidad viva en el Espíritu Santo. Es, asimismo, un tema actual. El papa Benedicto XVI, en su reciente (año 2010) Exhortación Apostólica Postsinodal, Verbum Domini (VD), afirma que «la Iglesia no vive de sí misma, sino del Evangelio, y en el Evangelio encuentra siempre de nuevo orientación para su camino» (VD 51). Más adelante, citando a San Jerónimo, se pregunta: "¿cómo se podría vivir sin la ciencia de las Escrituras, mediante las cuales se aprende a conocer a Cristo mismo, que es la vida de los creyentes?» (VD 72). Y en nuestro continente latinoamericano es, además, un tema metodológico. La teología misma es comprendida como hermenéutica, en donde la experiencia histórica concreta de la comunidad creyente y los cambios que presenta la realidad -particularmente en torno a la justicia-injusticia para con los pobres- son parte esencial de la interpretación bíblica, a modo de círculo hermenéutico ${ }^{1}$.

Como puede apreciarse, el tema es relevante, pero, a su vez, no fácil, porque tiene muchas aristas ${ }^{2}$. La relación entre Biblia e Iglesia depende

rpolanco@uc.cl

1 Cf. J. L. Segundo, Liberación de la teología (Buenos Aires 1975) 12.

2 Cf. Th. SöDing, «Exegetische und systematische Theologie im Dialog über den Schriftsinn", en Theologie und Philosophie 80 (2005) 490-516; íd., "Exegese und 
de una multitud de otras relaciones al interior de ella. Queremos, entonces, revisar algunas de aquellas relaciones, para tomar conciencia con mayor agudeza de esa tensión siempre necesaria y creadora en la vida de la comunidad creyente.

\section{Palabra y testigo}

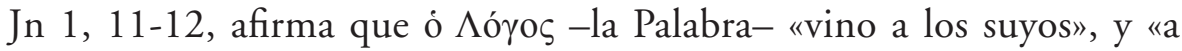
todos los que la recibieron les dio poder de hacerse hijos de Dios, a los que creen en su nombre». Si hemos sido creados por la Palabra - «todo se hizo por ella y sin ella nada se hizo" (Jn 1,3)-, acoger esa palabra significa escuchar su voz - una voz que no nos es ajena-, dejarse transformar por ese Logos, que es Jesucristo, «por quien existen todas las cosas, y nosotros por él» (1Cor 8,6$)$ y recibir un nuevo nacimiento, gracias al poder del Espíritu del Hijo, que en nosotros «clama: ¡Abbá, Padre!» (Gál 4, 6). En otras palabras, la obediencia al Logos produce una nueva creación, una creatura nueva, un pueblo nuevo. "Vemos aquí perfilarse el rostro de la Iglesia, como realidad definida por la acogida del Verbo de Dios que, haciéndose carne, ha venido a poner su morada entre nosotros» (VD 50). Esto nos habla, no de un acontecimiento puntual en el pasado -cuando el Verbo se hizo carne y habitó entre nosotros-, sino de una relación existencial entre la Palabra y la Iglesia. La Iglesia nace y vive de la Palabra: «Así Dios, que antiguamente habló, sigue hablando sin intermisión con la Esposa de su Hijo amado; y el Espíritu Santo, por quien la voz viva del Evangelio resuena en la Iglesia y, por ella, en el mundo entero, introduce a los creyentes en la plena verdad y hace habitar en ellos abundantemente la palabra de Cristo» (DV 8) ${ }^{3}$.

Pero -se preguntaba Pablo- "¿cómo creerán en aquel de quien no han oído hablar? ¿Cómo van a oír sin que se les predique? ¿Y cómo van a predicar si no son enviados?... Por tanto, la fe viene de la predicación, por la palabra de Cristo» (Rom 10, 14-15. 17). El rápido desarrollo de la misión primitiva se debe, en gran medida, a que cada discípulo se hace misionero, predicador, testigo del acontecimiento pascual ${ }^{4}$. A pesar de

Theologie. Spannungen und Widersprüche, Kohärenzen und Konvergenzen aus katholischer Perspektive», en Theologische Revue 99 (2003) 3-20.

3 Cf. VD 51.

4 Cf. J. Gnilka, Die frühen Christen. Ursprünge und Anfang der Kirche (Freiburg im Breisgau 1999) 219-274; R. Trevijano, Orígenes del cristianismo. El trasfondo judio del cristianismo primitivo (Salamanca ${ }^{2}$ 1996), 108-119. 365-400. 
que Jesús anunció el reino de Dios dentro de los confines de Israel, los primeros discípulos comprendieron, bastante luego, que la resurrección del Señor y la presencia del Espíritu del Resucitado en medio de ellos -como acontecimiento escatológico y realización del reino- les abría las puertas a una misión universal. Mateo es expresión de esa conciencia: «Id, pues, y haced discípulos a todas las gentes, bautizándolas en el nombre del Padre y del Hijo y del Espíritu Santo, y enseñándoles a guardar todo lo que yo os he mandado» (Mt 28, 19-20). Y es, específicamente, el Espíritu Santo el que concede a la comunidad naciente la fuerza y la animación para la misión encomendada: «Cuando el Espíritu Santo venga sobre vosotros, recibiréis una fuerza que os hará ser mis testigos en Jerusalén, en toda Judea y Samaria, y hasta los confines de la tierra» (Hech 1, 8). «El Nuevo Testamento insiste particularmente, entre los efectos del Espíritu, en el de unidad y en el de testimonio, que son fundamentales» ${ }^{5}$.

La relación entre Palabra e Iglesia pasa, entonces, por la relación testigo-Iglesia. No es una tensión entre libro/Biblia-Iglesia, simplemente, sino que pasa por una persona y el Espíritu que actúa en ella. El concepto de testigo-testimonio ( $\mu \alpha \rho_{\rho \tau \tau}$, $\mu \alpha \rho \tau v \rho i ́ \alpha$ ) es muy importante en la teología neotestamentaria ${ }^{6}$. En el corazón de cada creyente el Espíritu da testimonio de Jesús (Jn 15, 26s) y, por eso mismo, cada discípulo puede ser testigo de la resurrección y exaltación de Jesús en beneficio de su pueblo (Hech 5, 31-32). Testimoniar, en ese contexto, es afirmar que Jesús no es un hecho del pasado, sino un acontecimiento presente: el Espíritu hace que los discípulos no solo puedan afrontar las contradicciones del mundo (Hech 4,31), sino que se hagan parte de la historia de salvación como instrumentos al servicio del Evangelio. Les recuerda lo que Jesús ha dicho (Jn 14, 26) y los lleva a la verdad completa (Jn 16, 13). Se puede decir, entonces, que el Espíritu y los creyentes son cotestigos de la presencia actuante de Cristo en la Iglesia: «el Espíritu Santo y nosotros» (Hech 15, 28) ${ }^{7}$. Y eso, a lo largo de toda la historia, interpretando las Escrituras. La Iglesia nace y vive de la Palabra, pero esa dependencia de la Palabra pasa, en una primera tensión creadora, por una(s) persona(s) conducidas por el Espíritu. Ese aporte personal de cada creyente es ineludible, y es, a la vez, su riqueza y su tentación; es la presencia del santo o

\footnotetext{
5 Y. Congar, La tradición y la vida de la Iglesia (Andorra 1964),50.

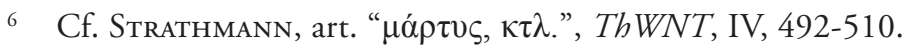

7 Cf. Y. Congar, La tradición y la vida de la Iglesia, 50-56.
} 
del iluminado, que debe ser discernida siempre pneumáticamente. Todo testimonio tiene algo de personal que en parte es evangélico y en parte puede no serlo. Es un aspecto del simul justus et peccator. Por eso la Iglesia siempre ha valorado a los santos como formas eminentes de testimonio profético y de autorizados intérpretes de la Sagrada Escritura.

Durante el siglo II el tema fue ocasión de una aguda reflexión cuando hubo que hacerle frente a la penetrante teología gnóstica. Su revisión nos mostrará un segundo aspecto. Los gnósticos -al menos los más cristianizados- valoraban el NT aun antes que en la Gran Iglesia existiera -propiamente- un canon, en cuanto "un corpus paralelo al AT». Y lo estimaban como una serie de obras de plena autoridad, contrapuestas en su teología a las Escrituras judías, y que eran, además, «revelación de Cristo, el Logos, el Hijo del Dios sumo». Para ello se servían de «una exégesis acentuadamente alegórica, a fin de hacer coincidir el dato escriturístico con su doctrina y utilizarlo como apoyo» ${ }^{8}$. Con ese obje-

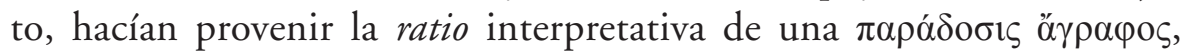
que «en la gnosis significa un contenido doctrinal que se da como de origen apostólico», "una tradición secreta recibida de los apóstoles»". Es un tema de hermenéutica en la Iglesia. Frente a ello, la Gran Iglesia, "contrapone en primer lugar no la Escritura, sino el principio de la sucesión ${ }^{10}$. Es decir, el testigo cualificado. Porque si, en efecto, "todos los cristianos son responsables de transmitir el Evangelio de generación en generación, una cosa es la transmisión, como tarea de todos, y otra cosa es custodiar, juzgar y definir como magisterio, que, como tal, es tarea de la jerarquía» ${ }^{11}$. «El oficio de interpretar auténticamente la palabra de Dios escrita o transmitida ha sido confiado únicamente al Magisterio vivo de la Iglesia, cuya autoridad es ejercida en nombre de Jesucristo", nos recuerda DV 10.

¿A qué responde esta solución eclesial, que le debe su formulación más lograda a Ireneo? A que «en la perspectiva del Nuevo Testamento la palabra es la palabra oída y, en cuanto tal, palabra anunciada, no palabra

8 M. Simonetti, Lettera elo allegoria. Un contributo alla storia dell'esegesi patristica (Roma 1985) 33.

9 J. Ratzinger, en K. Rahner - J. Ratzinger, Episcopado y primado (Barcelona 1965) 56. 53. Cf. también Ireneo, Adversus haereses, III,2,1-2.

10 J. Ratzinger, en K. Rahner - J. Ratzinger, Episcopado y primado, 60.

11 Y. Congar, La tradición y la vida de la Iglesia, 60. 
Polaridades en tensión para una adecuada interpretación de las Escrituras en la Iglesia | 91

leída. Esto quiere decir: si la verdadera successio apostolica reside en la palabra, no puede residir solo en un libro, sino que como successio verbi debe ser successio praedicantium, que no puede a su vez subsistir sin "misión”, o sea sin continuidad personal desde los apóstoles»" ${ }^{12}$. De hecho, el término griego $\delta \alpha \delta \delta \chi \eta ́$ significa tanto tradición como sucesión ${ }^{13}$. «En efecto, "tradición" no es mera transmisión anónima de doctrina, sino palabra viva, ligada a la persona, que tiene en la fe su realidad concreta. Y, viceversa, sucesión no es una recepción de poderes propios de la función, sobre los que el titular dispone, sino consiste en ser tomado uno al servicio de la palabra... y este oficio está por encima de su titular» ${ }^{14}$. Por eso Ireneo, en su argumentación, opone a la interpretación gnóstica, la lista de los obispos, cabezas de las iglesias, que se remontan hasta la misma persona de un apóstol. Y, afirma, que «por ese orden y sucesión esta Tradición está en la Iglesia a partir de los apóstoles y la predicación de la verdad llegó hasta nosotros. Y esto muestra plenamente que la fe vivificadora es única y la misma, la que viene de los apóstoles ha sido conservada y transmitida en la Iglesia hasta hoy» (Ad. haer. III, 3, 3). Esto se entiende solo si se reconoce que la sucesión «es firme mantenimiento de la palabra apostólica, como tradición significa la existencia continuada de testigos autorizados» ${ }^{15}$, que confirman que lo católico es lo que se ha enseñado siempre y en todo lugar (Ad. haer. I, 10, 2). Y esto explica también que, durante el siglo II, se aceptaran los escritos apostólicos como "escrituras» ${ }^{16}$, sin tener todavía un canon definido, porque había ya un criterio con el cual interpretarlos, que era la Tradición, entendida como regula fidei, garantizada por la sucesión episcopa ${ }^{17}$. Lo notable es que, frente a las «nuevas tradiciones ágrafas» de los gnósticos, la Iglesia contrapone no la «Escritura», sino la Tradición única de interpretación escriturística, garantizada por el testigo cualificado. El Lugdunense, incluso, nos dice: «Y si los apóstoles no nos hubiesen dejado las Escrituras, ¿acaso no hubiese sido necesario seguir el orden de la Tradición que ellos

12 J. Ratzinger, en K. Rahner - J. Ratzinger, Episcopado y primado, 58-59.

13 Cf. A. Bailly, Dictionnaire Grec Français (Paris 1950) s.v.

14 J. Ratzinger, en K. Rahner - J. Ratzinger, Episcopado y primado, 53.

15 J. Ratzinger, en K. Rahner - J. Ratzinger, Episcopado y primado, 54.

16 Cf. Ireneo, Adversus haereses, III,19,2; II,35,4. Cf. R. Polanco, El concepto de profecía en la teología de san Ireneo (Madrid 1999) 213-215.

17 Cf. S. Fernández, «Regula fidei et rationis. Tradición, razón y Escritura en los primeros siglos», en Teología y Vida 46 (2005) 103-121. 
transmitieron a quienes confiaban las iglesias?» (Ad. haer. III, 4, 1). Existe Tradición, porque en la Iglesia, que anuncia la palabra, se conserva la auctoritas apostolica ${ }^{18}$.

Se puede percibir ya claramente las diversas tensiones que esa realidad posee. Si la palabra es don conferido a la Iglesia, el creyente -y todo ser humano- es "oyente de la palabra», es decir, receptor de esa palabra, que se hace vida por la fe, porque «la fe viene de la predicación, y la predicación, por la palabra de Cristo» (Rom 10, 17). No se tiene poder sobre la palabra, sino que se cree, se obedece. El testigo cualificado es, en primer lugar, un creyente y, como tal, oyente. Pero a la vez, por su oficio, se presenta con autoridad frente a la comunidad, con capacidad de engendrar por la fe a la comunidad, todo lo cual determina una íntima relación con ella (cf. 1Cor 9, 16-19). El ministro es entonces creyente $y$ testigo en mutua polaridad. Y si es autoridad por el oficio, configurado como intérprete auténtico (LG, cap. III), eso no le asegura la autoridad

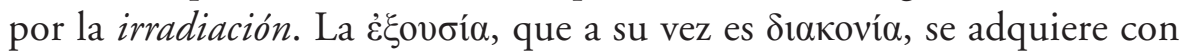
la vida, no simplemente con el oficio. De Jesús se decía que su $\dot{\varepsilon} \xi o v \sigma i \alpha^{19}$ no era como la de los escribas (Mt 7, 28-29). Juan, en línea con el AT, le llamará $\delta o ́ \xi \alpha(J n ~ 1,14)^{20}$. Ni el oficio depende de la autoridad, ni viceversa, son complementarias y ambas se necesitan. La palabra autorizada requiere no solo que sea verdadera, sino también creíble; de lo contrario, por verdadera que sea, no es fecunda, y eso la hace, en cierto sentido, también falsa, por irrelevante. He allí otra tensión, especialmente actual, debido a la configuración de la cultura moderna -que exige transparencia y testimonio más que verdades- y a las necesidades del mundo de los pobres -donde lo salvífico resulta ser, a fin de cuentas, lo verdadero, porque lo que salva es que sea una verdad para el hombre, es decir, una ortopraxis $^{21}$-. El testigo cualificado debe ser creíble, es decir, en primer lugar, un oyente, un creyente. Es la simple consecuencia de una eclesiología que comprende la Iglesia como Pueblo de Dios, en donde lo fundamental es común a todos y nace del bautismo antes que del orden: el seguimiento de Jesús, el servicio al mundo (LG, cap. II).

\footnotetext{
18 Cf. J. Ratzinger, en K. Rahner - J. Ratzinger, Episcopado y primado, 57.

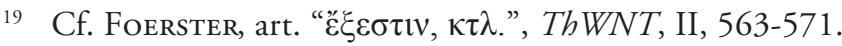

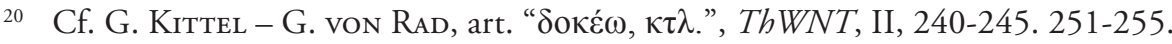

21 Cf. J. L. Segundo, El dogma que libera. Fe, revelación y magisterio dogmático (Santander 1989), 364-384.
} 
Una tercera tensión proviene del hecho que el testigo transmite lo que él mismo, a su vez, ha recibido. "La recepción es un proceso muy complejo, pausado y vital, a través del cual y con la asistencia del Espíritu Santo cada persona -y la comunidad- reconoce como un bien para sí mismo lo transmitido y configura, desde su propia realidad y en la interacción con otros, comprensiones nuevas de la palabra recibida, pero que lo son en la medida en que, a su vez, son formas auténticas de la fe apostólica $»^{22}$. La recepción es necesariamente contextualizada. Se recibe y se transmite desde un contexto determinado, lo cual implica, además de la necesaria tensión entre iglesias particulares e Iglesia universal, entre primado y colegio -tema que aquí no podemos abordar-, una necesaria dependencia del medio. En ese contexto, la recepción debe ser siempre fiel, aunque es también siempre creativa. Dicho de mejor manera, es creativa, precisamente para que sea realmente fiel. Todo eso nos habla de una tensión ahora con la significación para el contexto y su relación con la praxis eclesial que dicho contexto exige ${ }^{23}$. Estas ideas necesitan todavía desarrollo, pero antes, debemos describir otra línea de polaridades.

\section{EXPERIENCIA Y FORMULACIÓN.}

"Quiso Dios en su bondad y sabiduría revelarse a sí mismo y dar a conocer el misterio de su voluntad, mediante el cual los hombres, por medio de Cristo, Verbo hecho carne, en el Espíritu Santo tienen acceso al Padre y se hacen partícipes de la naturaleza divina» (DV 2). Es la experiencia fundante del cristianismo: los discípulos experimentaron que Jesús de Nazaret -el que fue crucificado-, ahora, se ha dejado ver y oír resucitado

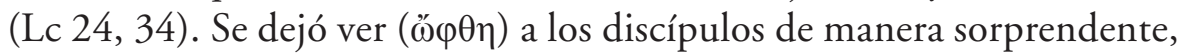
es decir, hay algo que ha sido visto inesperadamente, pero no es una simple existencia física, sino resucitada. Fue un encuentro con Jesús, un haber sido afectado y abordado totalmente por su presencia. Lo visto y oído por esos creyentes, y desde su fe, solo pudo ser expresado como

22 A. Antón, «La 'recepción’ en la Iglesia y eclesiología» en Gregorianum 77 (1996), 445-446. Cf. A. Antón, «La 'recepción’ en la Iglesia y eclesiología», 57-96. 437469; A. Scola, Chi è la Chiesa? Una chiave antropologica e sacramentale per l'ecclesiologia (Brescia 2005), 23-27.

23 Cf. A. Quiroz Magaña, Eclesiología en la teología de la liberación (Salamanca 1983), 311-336; J. M. Castillo, «Sacerdocio, episcopado, papado», en I. EllacuRÍA - J. Sobrino, Mysterium Liberationis. Conceptos fundamentales de la teología de la liberación, vol. II (Madrid 1990), 295-317. 
resurrección de Jesús. Los discípulos, desde su fe y lo vivido con Jesús de Nazaret, han interpretado ese encuentro como resurrección de entre los muertos por el poder del Padre, acontecimiento escatológico, el reino de Dios llegando definitivamente en Jesucristo, mediante su muerte ${ }^{24}$. La iniciativa es de Dios, que ha resucitado a su Hijo (Hech 2, 32), el cual, haciéndolos partícipes de su Espíritu, les ha comunicado la vida eterna del Padre (Ef 2, 18). Esa experiencia fundante, objetiva en su concreción misionera y subjetiva en su intensidad liberadora, a la hora de anunciarla a otros, se transforma en formulación. Pueden ser formulaciones muy breves (Rom 10, 9), discursos más elaborados (Hech 2, 14-36) o narraciones de distinto tipo (Evangelios sinópticos). Es el proceso paulatino de llevar la experiencia pascual a la palabra, lo que culmina finalmente en los textos del NT, aunque obviamente no solo en ellos, sino también en otras múltiples palabras. Lo importante de ese desarrollo es que, detrás de la variedad de formas de expresión, de teologías, de lenguajes, está el esfuerzo por hacer presente -hoy- ese evento escatológico único, que es Jesucristo muerto y resucitado y actuante en el Espíritu. Todas las palabras quieren conducir a la Palabra. Se puede percibir aquí el frágil equilibrio-tensión que todo ello supone. Por una parte, la variedad de teologías presentes en el NT no hacen sino mostrar la riqueza multiforme del evento Cristo, siempre inefable porque escatológico, siendo, a la vez -en línea teórica-, armónicas. Por otra parte, serán armonizadas auténticamente solo en referencia a ese único evento histórico relatado, pero que al mismo tiempo es actual y presente en la comunidad que lo proclama ${ }^{25}$. Es una tensión pasado-presente-palabra-comunidad. Memoria común que hace presente el acontecimiento pascual. Eso es lo que se llama proclamación, y no simple lectura de la palabra. La vida de la comunidad tiene una palabra que decir en la hermenéutica de esa palabra; palabra que, a su vez, la configura permanentemente como comunidad.

La Iglesia lo ha llamado inspiración. Es el desarrollo de las formulaciones, que culminan, finalmente, en el NT. «Lo revelado por Dios, que en los libros de la Sagrada Escritura se contiene y ofrece, se consignó por inspiración del Espíritu Santo (Spiritu Sancto afflante)»(DV 11).

24 Cf. J. Dunn, Jesus Remembered (Cambridge UK 2003) 866-879; W. Kasper, Jesús el Cristo (Salamanca 1994), 169-174.

25 Cf. B. Forte, La teologia come compagnia, memoria e profezia. Introduzione al senso e al metodo della teologia come storia (Milano 1987), 82-86. 
De acuerdo a lo ya afirmado acerca de la formulación de la experiencia fundante, se da una relación intrínseca entre el evento cristológico y la transmisión de esa fe apostólica. Entonces, si el acontecimiento pascual, como tal, es definitivo y universal, es decir, escatológico, ello implica que con la muerte de la generación apostólica -en sentido amplio- se demarca -más allá de lo simplemente histórico-cronológico-el contenido que puede ser llamado insuperable. Y si la experiencia pascual se transforma en palabra, a fin de ser comprendida y transmitida, entonces se produce una compenetración indisoluble entre el evento cristológico y la formulación apostólica. La fe formulada de la Iglesia apostólica se transforma así en fuente y norma obligada para la fe de la Iglesia de todo tiempo y lugar. Por tanto, tal como Dios tuvo cuidado que la revelación se llevara a cabo de manera adecuada, ha tenido cuidado que la formulación de esa revelación sea fiel a ese mismo evento, como dos aspectos de un mismo acontecimiento y que será el referente original permanente. La inspiración de la Sagrada Escritura, en su aspecto externo -y sin entrar aquí en el cómo se produce materialmente dicha inspiración-, es esa «aprobación apostólica del corpus textual destinado a garantizar la referencialidad requerida de la tradición de la fe mediante la objetivación verbal de su momento fundante... El acto con el cual Dios quiere y crea la Iglesia apostólica como norma perfecta e indefectible para la Iglesia del tiempo futuro, incluye de modo específico la constitución del corpus escriturístico en el cual (incluso el precedente veterotestamentario) se objetiva, en la forma histórica propia de una tradición verbal, la conciencia de la fe de la Iglesia originaria» ${ }^{26}$. Más allá de la definición que podamos dar de inspiración y de la compleja relación que se puede dar entre autor divino y humano (DV 11), lo concreto es que «habiendo hablado Dios en la Sagrada Escritura por hombres y a la manera humana» (DV 12), «el tema de la inspiración es decisivo para una adecuada aproximación a las Escrituras y para su correcta hermenéutica» (VD 19). Además, si la inspiración está en relación a la verdad salvífica de las Escrituras, ya que «los Libros de la Escritura enseñan firmemente, fielmente y sin error, la verdad que Dios quiso consignar en los libros sagrados para nuestra salvación» (DV 11), en una hermenéutica eclesial de las Escrituras, hay que considerar ambas: inspiración y verdad salvífica. «Sin embargo -lo

26 P. Sequeri, Il Dio affidabile. Saggio di teologia fondamentale (Brescia 1996), 642. Ver también págs. 634-645. El texto expone el pensamiento de K. RaHner, Inspiración de la Sagrada Escritura (Barcelona 1970). 
afirma el mismo papa Benedicto XVI-, debe ser reconocida la necesidad actual de investigar adecuadamente esta realidad, para responder mejor a lo que exige la interpretación de los textos sagrados según su naturaleza» (VD 19). Es una forma de decir que el concepto de inspiración es hoy complejo, al igual que «leer e interpretar la Escritura con el mismo Espíritu con que fue escrita» (DV 12). ¿Cómo decanta la inspiración en un texto? ¿En qué sentido un texto inspirado pudiera ser sometido a un trabajo interpretativo diverso de un texto no inspirado? ¿Qué significa, en concreto, considerar la inspiración en un trabajo hermenéutico? Son preguntas que merecen hoy una atención teológica.

La experiencia del evento escatológico que se ha formulado y objetivado en un corpus inspirado, no es sino fruto de la realidad institucional de la Iglesia. Es decir, en el caso de la Sagrada Escritura, se da, de una manera particular, la tensión propia de la Iglesia, en cuanto «la sociedad dotada de órganos jerárquicos y el Cuerpo místico... unam realitatem complexam efformant», de tal manera que «la articulación social de la Iglesia sirve al Espíritu de Cristo» (LG 8). La Iglesia, sacramento, comunión y misión, «ha sido constituida y organizada en este mundo como sociedad» (LG 8), como pueblo organizado. Por eso su carácter institucional es también parte de su esencia ${ }^{27}$. «Una institución es una estructura constituida por las formas históricas, relativamente estables y típicas, de una unidad social». Es una formación social que se presenta de un modo «relativamente autónomo respecto a sus miembros y respecto a su entorno; aparece como una unidad superior que es más que la suma de sus miembros y actúa de modo visible». Esta institucionalización de una unidad social tiene ciertamente valor, en cuanto objetivación de su identidad, pero a la vez, tiene su propia ambigüedad, en cuanto posee el riesgo de un formalismo que separe la dinámica de la comunidad de la vida real de los individuos. Todo esto «es aplicable a la Iglesia de modo análogo $»^{28}$. Ella tiene su necesario carácter institucional en determinadas manifestaciones objetivas de la fe común (expresión de la enseñanza, la

27 Cf. M. KeHL, La Iglesia. Eclesiología católica (Salamanca 1996), 360-372; M. Kehl, «Kirche als Institution», en W. Kern - H. J. Pottmeyer - M. Seckler (eds.), Handbuch der Fundamentaltheologie, III Traktat Kirche (Freiburg im Breisgau 1986) 176-197; H. von BALTHASAR, Teodramática. III Las personas del drama: las personas en Cristo (Madrid 1993) 325-330; H. von Balthasar, Pneuma und Institution, Skizzen zur Theologie IV (Einsiedeln 1974) 229-235.

M. KeHL, La Iglesia, 361-363. 
liturgia, la comunión y el servicio al mundo), algunas modificables a lo largo de la historia, y otras que pertenecen irrenunciablemente a la expresión de su fe. Entre estas últimas se cuenta la Sagrada Escritura, que «es la palabra de Dios en cuanto fue consignada por escrito por la inspiración del Espíritu Santo» (DV 9). Aquí se dan las tensiones propias de una institución que es guiada por el Espíritu, un Espíritu que, a la vez, no está sujeto a ninguna institución, porque sopla donde quiere (cf. Jn 3, 8). «El Espíritu guía a la Iglesia a toda la verdad» (cf. Jn 16, 13) «con diversos dones jerárquicos y carismáticos» (LG 4). El Espíritu se sirve de la textura institucional de la Iglesia -en nuestro caso, de la Sagrada Escritura- para darle su identidad como comunidad de Cristo resucitado y para integrarla en la unidad diacrónica y sincrónica que se llama comunión. Pero, a la vez, ese mismo Espíritu Santo «ofrece a todos la posibilidad de asociarse, de un modo por Dios conocido, al misterio pascual de Cristo» (GS 22), lo cual implica una palabra más allá de la Escritura. Es la doble tensión, primero, entre Pneuma vital y estructura humana, que se transforma aquí en tensión entre Escritura -norma normans non normata- y el resto de las formas institucionales, también las irrenunciables. La historia de esa relación es muy fluctuante ${ }^{29}$. Y la otra tensión entre Escrituras cristianas y otros textos sagrados, en donde el Espíritu también se hace presente con bondad y verdad salvífica, aunque no se les aplique el concepto de inspirados ${ }^{30}$. Este tema es de mucha actualidad y necesidad en el diálogo interreligioso. En este último punto la reflexión apenas comienza.

29 Como ejemplo se podría aducir todo el desarrollo de la teología del sacramento del orden. Es claro que el desarrollo de la vida de la Iglesia ab antiquo (LG 28) ha sido tanto o más relevante que la Sagrada Escritura en la configuración de ese sacramento surgido ex divina institutione (LG 20). "Así, el ministerio eclesiástico, de institución divina, es ejercido en diversos órdenes por aquellos que ya desde antiguo vienen llamándose Obispos, presbíteros y diáconos» (LG 28). La historia y las preguntas que hoy se le formulan a este sacramento muestran lo complejo que ha sido reconocer el fundamento bíblico, tanto de su momento institucional por parte de Jesús (que ha fluctuado desde la última Cena hasta el envío apostólico), como de sus características irreformables. Cf. K. Osborne, Priesthood. A History of Ordained Ministry in the Roman Catholic Church (Eugene OR 2003); L. OтT, El sacramento del Orden (Historia de los Dogmas IV,5; Madrid 1976); E. CastellucCI, Il ministero ordinato (Brescia $\left.{ }^{2} 2006\right)$ 11-288.

30 Cf. Declaración Dominus Iesus sobre la unicidad y la universalidad salvífica de Jesucristo y de la Iglesia, 8 . 
Todo lo anterior implica entender la catolicidad -totalidad- como una forma estructural de la fe, y por lo tanto, como un principio formal del cristianismo ${ }^{31}$. Si el ser humano, por el conocimiento y la libertad, se va realizando a sí mismo a lo largo de su vida, de tal manera que la historia es parte de su esencia en el sentido de una autotrascendencia, en donde llega a ser él mismo solo al final de su vida y en Dios, pero siendo, a la vez, ya desde el comienzo, sí mismo ${ }^{32}$; algo semejante ocurre con la Iglesia: tiene "que realizarse siempre de nuevo según la situación histórica" ${ }^{33}$, y estará plena solo en la escatología. "No es solo factum dado, sino faciendum encomendado ${ }^{34}$. Esto surge del mismo acto de fe con el que cada persona se incorpora a la Iglesia: es adhesión a una comunidad de fe, que antecede al propio creyente, pero que, a la vez, se ve enriquecida por ese nuevo miembro que vive de manera personal y comunitaria su fe. La Iglesia es un nosotros «que trasciende al simple yo ${ }^{35}$ y media "entre ser y tiempo». En Dios, «el ser está contenido como tiempo», y la Iglesia -también la humanidad- «puede fundamentar la unidad de la historia porque Dios le ha dado memoria» ${ }^{36}$. La Iglesia resiste el tiempo al ser espacio común de la fe, un sujeto único - gracias a la

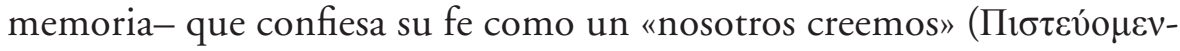
Credimus: DH 125; 150). Entonces el ser humano crea la historia, y ella misma, en inseparable conexión, lo constituye propiamente en hombre. La memoria fundamentadora permite a lo humano superar el efímero momento de su existencia presente. «El espíritu muestra su ser espíritu como memoria, la memoria fundamenta la tradición, la tradición se realiza en la historia, la historia, como cohesión previamente dada del

31 J. Ratzinger, Teoría de los principios teológicos. Materiales para una teología fundamental (Barcelona 1985), 10s. Cf. R. Polanco, "Ontología e historia en el pensamiento de Joseph Ratzinger», en Teología y Vida 52 (2011) 479-501.

Cf. K. Rahner, art. "Hombre», en Sacramentum Mundi, 3 (Barcelona 1984), 495.

33 A. Vigueras, «La teología práctica de Karl Rahner: Una teología pastoral en perspectiva escatológica» en Teología y Vida 51 (2010) 471.

34 K. Neumann, Der Praxisbezug der Theologie bei Karl Rahner (Freiburg 1980) 384, citado por A. Vigueras, "La teología práctica de Karl Rahner», 471.

35 J. Ratzinger, Iglesia, ecumenismo y política. Nuevos ensayos de eclesiología (Madrid 1987) 36. En estas ideas, el autor se reconoce deudor de H. MüHLEn, Una mystica persona. Die Kirche als das Mysterium der heilsgeschichtlichen Identität des Heiligen Geistes in Christus und den Christen. Eine Person in vielen Personen (Paderborn 1964) y de H. De Lubac, Catholicisme. Les aspects sociaux du dogme (Paris 1938).

36 J. Ratzinger, Teoría de los principios teológicos, 24-25. 
ser humano, posibilita a su vez a este ser humano, que, sin la relación necesariamente transtemporal de la con-humanidad, no puede crecer hasta llegar a sí mismo ni es capaz de expresarse». La memoria se convierte en tradición en su exteriorización, es decir, en su participación a otros, lo cual implica que asume una forma de lenguaje como medio y contenido de la misma tradición, en donde el lenguaje -en particular aquí la Sagrada Escritura- «cumple su función creadora de unidad esencialmente como dado, como recibido ${ }^{37}$, aunque siempre abierto a las nuevas experiencias de las nuevas generaciones.

Este sujeto único en la historia y en la geografía, que el Credo lo ha llamado catolicidad, y que «en la antigüedad parecía querer indicar la totalidad $-\kappa \alpha \theta^{\prime}$ ö $\lambda o v-$ de la Iglesia en relación a las iglesias particulares que la conformaban, a partir de la disputa donatista, particularmente con Optato de Milevi y Agustín, se comenzó a comprender en el sentido de comunión universal, en oposición a las iglesias donatistas extendidas solo por África del Norte» ${ }^{38}$. Es la universalidad en su amplio sentido. Esta universalidad tiene una importancia fundamental para el tema que tratamos: un sujeto único implica que cada expresión de la historia, en cuanto expresión de la fe auténtica y en su relación a la totalidad y a la Escritura, es parte esencial de dicha fe, y a la vez, es transitoria. Esencial porque auténtica: la Tradición es la fe vivida por la comunión eclesial ${ }^{39}$, en donde «bajo la asistencia del Espíritu Santo, la Iglesia progresa (proficit), es decir, crece en la comprensión de las cosas y de las palabras transmitidas", y así, «en su doctrina, vida y culto perpetúa y transmite a todas las generaciones todo lo que ella es, todo lo que cree» (DV 8). Pero igualmente, transitoria, ya que la fe vivida de la Iglesia, como acontecimiento pascual, «nunca se agota con su formulación explícita ${ }^{40}$. Asimismo, en un cierto aspecto, toda expresión de la fe es normativa $-\mathrm{y}$ en ese sentido requiere la obediencia de la fe-, ya que «la Sagrada Tradición transmite íntegramente a los sucesores de los Apóstoles la palabra de Dios, a ellos confiada por Cristo Señor y por el Espíritu Santo»(DV 9). Así, pues, «la fe vivida de la Iglesia y su inteligencia de sí misma son también la norma

37 J. Ratzinger, Teoría de los principios teológicos, 100-102.

38 A. Dulles, Models of the Church (Expanded edition) (New York 2002) 116.

39 Cf. K.-H. Weger, art. "Tradición», en Sacramentum Mundi, 6 (Barcelona 1984), 691-703.

40 K.-H. Weger, art. «Tradición», en Sacramentum Mundi, 695. 
última de la crítica intraeclesiástica a la tradición $»^{41}$. Pero a la vez, están esencialmente sometidas a la crítica de la totalidad y de la Escritura, ya que como históricas adquieren siempre elementos provisorios, y como llevada adelante por pecadores, adquieren también elementos espurios, necesarios de eliminar. Por lo tanto sometidos al discernimiento de la comunidad eclesial, desde la propia fe. Los ejemplos a lo largo de la historia son múltiples ${ }^{42}$. De todo aquello se deduce el principio hermenéutico de la tradición: «el significado concreto y la autoridad específica de cada una de las huellas dejadas en la historia por la tradición postapostólica pueden ser determinados únicamente dentro de un proceso dialógico entre la Iglesia de hoy y la Sagrada Escritura» ${ }^{43}$. He ahí la tensión fundamental, cuyo criterio rector debe ser la integración de la fe en la totalidad diacrónica y sincrónica de la Iglesia, la adecuación a la palabra escrita proclamada, y la significatividad salvífica para el presente. Si es palabra de salvación, entonces lo que necesita salvación, y qué es salvación hoy, son también criterios ineludibles, como bien lo ha destacado la teología latinoamericana ${ }^{44}$.

Finalmente, en una Iglesia sujeto único, la persona individual, «con su fe y su Biblia», no pierde su centralidad, ni su capacidad de entender la Escritura. Pero lo ha de hacer desde su responsabilidad particular, que se ha manifestado en la profesión de fe personal en el bautismo (LG 33), y en la "personalización del acontecimiento cultual» ${ }^{45}$ en la Iglesia. Su lugar y su aporte se da en una comunión de libertades, que como individuo no lo disuelve en medio de una masa, sino que lo fortalece desde la comunión con Cristo ("ya no vivo yo, sino Cristo vive en mí» [Gál 2, 20]), cuya voluntad humana ha llegado a ser una con su voluntad divina en el sí único a la voluntad del Padre, en la única forma de existencia que es la total dependencia y filiación eterna con respecto al Padre. De esta manera se puede hablar también de una hermenéutica de comunión.

41 K.-H. Weger, art. «Tradición», en Sacramentum Mundi, 695.

42 Precisamente porque es un sujeto único a lo largo de la historia, la Iglesia puede y debe pedir perdón y, en donde es posible, reparar por los pecados cometidos en otra época y por personas que ya no viven.

43 Cf. K.-H. Weger, art. «Tradición», en Sacramentum Mundi, 691-703.

44 Cf. J. L. Segundo, Libertad y liberación, en Mysterium Liberationis, I, 373-391; A. Quiroz Magaña, Eclesiología en la teología de la liberación (Salamanca 1983) 96-113.

45 J. Ratzinger, Iglesia, ecumenismo y política, 39. 
Polaridades en tensión para una adecuada interpretación de las Escrituras en la Iglesia | 101

Cada bautizado -y cada ser humano-, en la comunión con el Resucitado, tiene el Espíritu del Padre, porque nos hacemos «un solo espíritu con él» (1Cor 6, 17), lo cual nos permite asociarnos al misterio pascual y así "comprender» y aportar -cada uno desde su contexto vital- a la revelación salvífica que acontece permanentemente en Cristo.

\section{El reino anunciado por Jesús, el Espíritu Santo y la Iglesia}

Un último gran aspecto, que puede ser considerado como conclusión, es la implicancia hermenéutica de la relación cristología-pneumatología en la Iglesia.

La relación Escritura-Iglesia -que estamos estudiando- está en íntima conexión con la relación Jesús-Iglesia, ya que la cualidad hermenéutica de la Iglesia le viene de su dependencia de Jesús y de cuán presente esté el Espíritu del Señor en ella. Ya en el NT aparece el origen de la Iglesia ligada al acontecimiento de Pentecostés (Hech 2) y a la misión de los apóstoles, vinculados a su vez a una voluntad explícita de Jesús (Mc 3, 13-19; Mt 28, 16-20). Los mismos Evangelios presentan en Jesús algunos elementos precursores de la futura Iglesia (Mt 16, 13-20; Lc 22, 14-20 ${ }^{46}$. «En Pablo encontramos elaboradas, a partir de la cristología, algunas consecuencias eclesiológicas (Rom 1, 1-6; Flp 2, 5-11) y sus dos Cartas a los Corintios presentan reflexiones eclesiológicas todavía más acabadas. Pero es solo con la tercera generación cristiana que encontramos el tema «Iglesia» desarrollado más centralmente en el NT, buscando siempre responder a cuestiones sobre la identidad y la esencia de la comunidad cristiana (Mt, Lc-Hech, Ef). La eclesiología ha surgido desde la cristología. Desde la fe en el Resucitado, como resultado de la reflexión acerca de la propia experiencia vital y comunitaria, y respondiendo a la pregunta por Jesús, el Mesías, y por la salvación que ha traído, se fue elaborando la teología sobre la Iglesia ${ }^{34}$.

No es el momento de estudiar la fundamentación crítica de la institución de la Iglesia por parte de Jesús, ni las etapas por las que dicha reflexión ha pasado, desde la Ilustración en adelante. La bibliografía es

46 Cf. S. Pié-Ninot, Eclesiología. La sacramentalidad de la comunidad cristiana (Salamanca 2007) 101.

47 J. Roloff, Die Kirche im Neuen Testament (Göttingen 1993) 11-12. 
abundante ${ }^{48}$. Simplemente, a la luz de Lumen gentium, hay que afirmar que el origen de la Iglesia es, en primer lugar, mistérico: «El Padre eterno... estableció convocar a quienes creen en Cristo en la santa Iglesia» (LG 2). "Así toda la Iglesia aparece como "un pueblo reunido en virtud de la unidad del Padre y del Hijo y del Espíritu Santo" (Cipriano)» (LG 4). Y ese «misterio de la santa Iglesia se manifiesta en su fundación. Pues el Señor Jesús dio comienzo a su Iglesia predicando la buena nueva, es decir, la llegada del reino de Dios prometido desde siglos en la Escritura» (LG 5). Esa fundación, sin embargo, es de carácter implícito. «Para realizar su misión salvífica, Jesús ha querido reunir a los hombres en orden al Reino y convocarlos en torno a sí. En orden a este designio, Jesús ha realizado actos concretos, cuya única interpretación posible, tomados en su conjunto, es la preparación de la Iglesia, que será definitivamente constituida en los acontecimientos de Pascua y Pentecostés» ${ }^{49}$. Es lo que W. Trilling ha llamado "eclesiología implícita " ${ }^{50}$,en el sentido de que Jesús lleva adelante definitivamente la realización de su reino iniciado en el Antiguo Testamento, y que se confía después de pascua a la Iglesia» ${ }^{51}$.

La pregunta entonces no ha de ser, en primer lugar, sobre la intención explícita de Jesús - por lo demás difícil hoy de percibir-, sino fundamentalmente sobre el significado de sus palabras y obras intrínsecamente conexas (DV 2). Aplicado esto a la predicación del reino por parte de Jesús, dado su carácter fundamentalmente interpelativo y no simplemente informativo (Mc 1, 14-15), implica que los oyentes de ese mensaje se experimentan como los llamados, los elegidos (Mc 13, 20; 1Cor 1, 2) $\mathrm{y}$, por lo tanto, como un grupo proyectado hacia la formación de una comunidad. Además la salvación que se cumple presenta una dimensión de comunión, el reino de Dios es una expresión de comunión, y por lo tanto, presenta esencialmente una dimensión social. «La estructura del seguimiento marca para todo tiempo el significado y valor de la Ekklesía. En ella es decisivo el primado de Jesús, que como enviado de Dios, el

48 Da cuenta de lo más importante S. Pié-Ninot, Eclesiología, 101-113.

49 Comisión Teológica Internacional, «La conciencia que Jesús tenía de sí mismo y de su misión (1985)», en Documentos 1969-1996. Veinticinco años de servicio a la teología de la Iglesia (Madrid 1998), 386. Cf. íd. "Temas selectos de Eclesiología (1984)», en Documentos, 330-334.

50 W. Trilling, Die Botschaft Jesu. Exegetische Orientierungen (Freiburg im Breisgau 1978) 57-72.

51 S. Pié-Ninot, Eclesiología, 109. 
Polaridades en tensión para una adecuada interpretación de las Escrituras en la Iglesia | 103

Padre, la funda». "Jesús reúne una comunidad de personas que creen, esperan y aman..., porque la comunidad necesita de los creyentes para dar su testimonio, celebrar su liturgia y ejercitar su amor al prójimo» ${ }^{52}$. «Esto quiere decir que el significado del mensaje del reino de Dios no se puede comprender independientemente de un análisis de la recepción de tal mensaje». Lo cual indica que «la pregunta por la legitimación de la Iglesia por parte de Jesús no puede ser resuelta convenientemente fuera de la Iglesia " ${ }^{53}$. En efecto, «la revelación de Dios, de hecho, no habría alcanzado a los hombres y mujeres del mundo, si no hubiese sido acogida con la fe, por obra del Espíritu Santo, y luego no hubiese sido testimoniada desde la misma fe vivida. La comunidad eclesial, como autoentrega de Dios, es colaboración indispensable de la misma revelación ${ }^{54}$. $\mathrm{Si}$ la Iglesia es recepción y testimonio desde la fe, entonces la misma fe es condición hermenéutica indispensable para una comprensión global del fenómeno cristiano -Escritura incluida-, si bien esto no quita todos los accesos parciales posibles, en la medida en que aquellos sean precisamente eso: accesos parciales a integrar en la catolicidad.

Esta mirada desde la fe es lo que afirma el Credo cuando confiesa, desde antiguo, credo... Ecclesiam... Significa que la Iglesia no solo es sujeto de la fe, sino también objeto de esa misma fe, en cuanto es lugar e instrumento de la acción del Espíritu Santo en el mundo, y lugar desde donde proclamamos nuestra fe en Dios, que es Padre, Hijo y Espíritu Santo ${ }^{55}$. Si volvemos ahora, un instante, al siglo II, momento de altísima

52 TH. SöDIng, Jesus und die Kirche. Was sagt das Neue Testament? (Freiburg im Breisgau 2007) 257. Cf. TH. SöDing, Jesus und die Kirche. Was sagt das Neue Testament?, 73-88.

53 H-J. Verweyen, Gottes letztes Wort. Grundriss der Fundamentaltheologie (Düsseldorf 1991) 491-492.

54 W. Kasper, «Das Verhältnis von Schrift und Tradition. Eine pneumatologische Perspektive»: Theologische Quartalschrift 170 (1990) 186.

55 En todo caso, el texto latino hace una diferencia entre el credo 'in'... Deum..., y el credo... Ecclesiam..., sin artículo. No hay, literariamente, diferencia de significado. Se puede decir con o sin artículo, significando, en ambos casos, lo mismo. La diferencia es más bien de orden teológico: no es lo mismo creer en Dios, como Dios, que creer en la Iglesia, como lugar de la acción de Dios. Son dos actos humanos de muy distinto significado y consecuencias existenciales. Cf. A. Antón, La Iglesia de Cristo. El Israel de la Vieja y la Nueva Alianza (Madrid 1977), 54-64; íd., El misterio de la Iglesia. Evolución histórica de las ideas eclesiológicas, I (Madrid 1986) 8-11; J. RATZINGER, Introducción al cristianismo (Salamanca 2005), 275-279. 
importancia para la evolución del dogma, este mismo tema se presentó en la disputa con el gnosticismo bajo la forma de controversia fe-gnosis. Frente a la propuesta del gnosticismo de una salvación entendida como gnosis de la propia naturaleza, la Gran Iglesia reafirmó su anuncio de la salvación entendida como fe en Jesús de Nazaret, ya que la fe, como actitud humana integral, es conocimiento perfecto (Ad. haer. III,1, 1), ya que es amor (Ad. haer. IV, 12,2): «El conocimiento de salvación ( $\gamma v \tilde{\omega} \sigma 1 \varsigma$ $\Sigma \omega \tau \eta$ pías - agnitio Salutis [Lc 1,77]) es el conocimiento del Hijo de Dios, que es salvación, Salvador y fuerza salvadora... es Salvador porque es el Hijo y Verbo de Dios, es fuerza salvadora porque es Espíritu... y es salvación porque es carne» (Ad. haer. III, 10, 3) $)^{56}$. Es claro que el perfecto conocimiento, que es amor, necesita de la fe en el Hijo de Dios hecho carne.

De aquí nace «un criterio fundamental de la hermenéutica bíblica: el lugar originario de la interpretación escriturística es la vida de la Iglesia» (VD 29). El papa Benedicto XVI, citando a San Buenaventura, afirma que "sin la fe, falta la clave de acceso al texto sagrado: "Éste es el conocimiento de Jesucristo, del que se derivan, como de una fuente, la seguridad y la inteligencia de toda la sagrada Escritura. Por eso, es imposible adentrarse en su conocimiento sin tener antes infundida la fe de Cristo, que es faro, puerta y fundamento de toda la Escritura" ${ }^{57}$. Pero la referencia eclesial no es, ni puede ser, un criterio extrínseco, al margen del texto mismo. Siendo la Biblia el libro de la Iglesia, «su verdadera hermenéutica brota de su inmanencia en la vida eclesial» (VD $29)^{58}$. Hemos dicho que esto no obsta para todo tipo de aproximaciones al texto bíblico, sino que implica, simplemente, que es necesaria «una afinidad fundamental entre el intérprete y su objeto. La hermenéutica es un proceso dialéctico: la comprensión de un texto es siempre una comprensión más amplia de sí mismo». Así pues, «el sentido de un texto no se da plenamente si no es actualizado en la vivencia de lectores que se lo apropian. A partir de su situación, éstos son llamados a descubrir significaciones nuevas, en la línea del sentido fundamental indicado por

56 Cf. A. Rousseau - L. Doutreleau, Contre les Hérésies. Livre III, Tome I (SC 210; Paris 1974) 271-273 (Notes justificatives p. 125, n.1-3).

57 VD 29, citando: Breviloquium, Prol., Opera Omnia, V (Quaracchi 1891) 201-202.

58 Cf. Th. SöDing, Jesus und die Kirche. Was sagt das Neue Testament? (Freiburg im Breisgau 2007), 40. 
Polaridades en tensión para una adecuada interpretación de las Escrituras en la Iglesia $\mid 105$

el texto" 59 . Y ya que "las tradiciones de fe forman el medio vital en el cual se ha insertado la actividad literaria de los autores de la Sagrada Escritura», y que "esta inserción comprendía también la participación en la vida litúrgica y en la actividad exterior de las comunidades, en su mundo espiritual, su cultura, y en las peripecias de su destino histórico»; «la interpretación de la Sagrada Escritura exige, pues, de manera semejante, la participación de los exegetas en toda la vida y la fe de la comunidad creyente de su tiempo ${ }^{60}$. Todo esto, no cabe duda, plantea fuertes desafíos a la apertura a métodos cuya matriz filosófico-antropológica son a veces muy diversos entre sí y del pensamiento eclesial, y que precisamente por eso son necesarios de explorar. En todo caso, son caminos indispensables para abrir nuevas intelecciones dentro de una Tradición bimilenaria.

Este lugar originario de interpretación es la comunidad conducida por el Espíritu Santo, el cual hace presente, precisamente, al Resucitado. Es lo que Juan afirma cuando dice que el Espíritu Santo «os lo enseñará todo y os recordará todo lo que yo [= Jesús] os he dicho» (Jn 14, 26). El Espíritu enseña recordando, esto es, existe una fuerte tensión entre nuevas comprensiones y un hecho histórico ya acontecido y plasmado por escrito, que al ser proclamado hoy, se hace nuevamente presente. Pero a la vez enseña anticipando ya que el que se hace presente es el Resucitado, escatología presente en la historia. Es lo definitivo adelantándose en la historia. "La Iglesia, como sujeto único, es la condición de posibilidad para acoger la traditio Iesu que se hace realidad histórica y configuradora de la historia» ${ }^{61}$, es decir, se hace Tradición, fe vivida, presencia pneumática de Cristo. Así el Espíritu Santo actúa siempre como intérprete del Resucitado, manteniendo su palabra constantemente actual y nueva. Memoria, en este contexto, significa "descubrir el sentido del hecho Jesús, y hacerlo significativo». "Este recordar es una comprensión guiada por el Espíritu Santo; recordando, el creyente entra en la dimensión profunda de lo sucedido y ve lo que no era visible desde una perspectiva meramente externa». "Es un ser guiados por el Espíritu Santo, que nos muestra la cohesión de la Escritura, la cohesión entre palabra y realidad,

59 Pontificia Comisión Bíblica, La interpretación de la Biblia en la Iglesia, II/A/1 (Santiago 1994) 70-71, haciendo referencia a Gadamer y Ricoeur respectivamente.

60 Pontificia Comisión Bíblica, La interpretación de la Biblia en la Iglesia, III/A/3 (Santiago 1994), 87-88.

61 J. Ratzinger, Teoría de los principios teológicos, 117. 
guiándonos así "a la verdad plena" (Jn 16, 13)». En consecuencia la Sagrada Escritura, como libro inspirado, "supera la dimensión personal y en lo más profundo es guiado por el Espíritu de Dios, que es el Espíritu de la verdad», y así «abre también un camino de comprensión, un camino que permanece siempre unido a esta palabra y que, sin embargo, puede y debe guiar de generación en generación, de manera siempre nueva, hasta las profundidades de la "verdad plena" (Jn 16, 13)»"

Ahora, si tomamos en cuenta que el Espíritu, que es el Pneuma divino de la creación (Veni creator Spiritus. Cf. Sal 104), hace presente al Logos, ratio universalis, que se ha hecho carne (Jn 1, 14), "uniéndose en cierto modo a todo ser humano" (GS 22), entonces las posibilidades de interpretaciones nuevas han de ser tan amplias como es la humanidad: nibil humanum a me alienum puto (Terencio). Todo lo humano ha de caber de alguna manera en la Palabra revelada en Cristo (Heb 1, 1-3). Hoy día, me parece, esto no es, en primer lugar, un desafío para la hermenéutica, sino, sobre todo, para la Iglesia en su autocomprensión. Ya que la vida de la Iglesia es lugar originario de la interpretación escriturística, ¿qué consecuencias eclesiológicas y por lo tanto hermenéuticas se han de extraer de la comprensión conciliar de la Ecclesia universalis, compuesta por «todos los justos desde Adán, desde el justo Abel hasta el último elegido (S. Gregorio Mago, S. Agustín, S. Juan Damasceno)» (LG 2)? Esa Iglesia universal no se da solo en la eternidad, sino ya desde ahora, de una manera conocida por Dios, pero que tiene una relevancia para nosotros en cuanto también es "lugar originario de hermenéutica». Tema que merece una reflexión mucho más atenta.

Tal vez una línea de profundización la podemos encontrar en el concepto de forma (Gestalt) que plantea Hans Urs von Balthasar ${ }^{63}$. Para este gran autor, la forma es la estructura concreta del ser, una unidad que informa y traspasa todo. La forma es también aparición de lo divino, es el lenguaje del Espíritu. Por lo tanto la revelación o manifestación de Dios, por ser el creador, ha de tener la forma misma del mundo: como irradiación y gloria. El mundo, como tal, simplemente prepara la

62 J. Ratzinger-Benedicto XVI, Jesús de Nazaret. Desde el Bautismo a la Transfiguración (Santiago 2007) 275-279.

63 Lo hace en su conocida Trilogía, particularmente, en la primera parte: H. von Balthasar, Gloria, 7 vol. (Madrid 1985-1989); Teodramática, 5 vol. (Madrid 1990-1997); Teológica, 3 vol. (Madrid 1997-1998); Epílogo (Madrid 1998). 
Polaridades en tensión para una adecuada interpretación de las Escrituras en la Iglesia $\mid 107$

manifestación definitiva en la unión hipostática, que significa que "este hombre» es Dios mismo. Se une el arquetipo y la imagen. La unidad del Hijo eterno y del hombre temporal hace definitiva esa revelación y ese lenguaje, que pasa a ser el lenguaje de la carne. Todo esto nos lleva a la íntima relación entre cristología y ontología. Cristo es palabra humana de Dios para el mundo, que hace que toda palabra verdaderamente humana, hable de Dios ${ }^{64}$. Desafío presente hoy para la Iglesia: que esas palabras humanas, realmente hablen, o mejor, que las escuchemos, que tengamos oídos cristológicos para oír a todo ente.

Concluyamos: Dios es invisible. Esto es evidente. «Entonces, ¿̨puede "algo" de Dios llegar a ser visible: el Logos en la carne, el Espíritu en la Iglesia, la palabra en el libro?»" ${ }^{65}$ Esta ha sido la tensión fundamental que ha estado en la base de nuestras reflexiones y que está, en el fondo, en la base de nuestra vida eclesial y humana. San Agustín lo expone con la belleza y penetración que lo caracterizan: Quid dicit aliquis, cum de te dicit? Et vae tacentibus de te, quoniam loquaces muti sunt (Confesiones I, 4, 4). "¿Qué cosa dice, el que habla de ti? Y sin embargo, infelices son los que no hablan de ti, porque son charlatanes mudos». Esa es la terrible atracción de la fe, y la preciosa tarea de la teología.

64 Estas ideas se encuentran en Gloria, I, passim; Teológica, II, 238-264; Zu seinem Werk (Freiburg 22000) 74.

65 J. Werbick, Kirche. Ein ekklesiologischer Entwurf für Studium und Praxis (Freiburg im Breisgau 1994) 17. 
Resumen: El artículo muestra las diversas polaridades en tensión -necesarias y enriquecedoras- que existen en todo el proceso de interpretación de las Escrituras en la Iglesia. La Palabra, que es siempre proclamada por un testigo, presenta toda una gama de polaridades entre lo personal y lo institucional y entre Pneuma e institución. Tradición y creatividad, experiencia y formulación, individuo y comunidad son otras tantas polaridades que deben mantenerse en adecuado equilibrio. Se concluye que la relación Jesús e Iglesia, en los comienzos del cristianismo, como también la relación actual entre cristología y pneumatología, implica toda una polaridad que abarca a las anteriores y que de alguna manera permite comprender este fenómeno vital y de fe que se llama interpretación eclesial de la Escritura.

Palabras clave: Escritura, Espíritu, Iglesia, tradición, historia, hermenéutica, exégesis

Abstract: The article shows the various polarities in tension -necessary and enriching- that exist throughout the interpretation process of the Scriptures in Church. The Word, which is always proclaimed by a witness, presents a range of polarities between the personal and institutional spheres and between Pneuma and institution. Tradition and creativity, experience and formulation, individual and community are many other polarities that must be kept properly balanced. It is concluded that the relation between Jesus and the Church, at the beginning of Christianity, as well as the current relation between Christology and Pneumatology, involves a complete polarity which includes the former and that somehow allows the understanding of this vital phenomenon of faith that is called the ecclesiastical interpretation of the Scripture.

Keywords: Scripture, Spirit, Church, tradition, history, hermeneutics, exegesis 